\title{
Turning the Halide Switch in the Synthesis of Au-Pd Alloy and Core-Shell Nanoicosahedra with Terraced Shells: Performance in Electrochemical and Plasmon-Enhanced Catalysis
}

\author{
Shih-Cheng Hsu, ${ }^{\dagger}{ }^{\perp}$ Yu-Chun Chuang, ${ }^{\ddagger}$ Brian T. Sneed,${ }^{\S}$ David A. Cullen,, Te-Wei Chiu, ${ }^{\perp}$ and \\ Chun-Hong Kuo*,† \\ ${ }^{\dagger}$ Institute of Chemistry, Academia Sinica, Taipei 11529, Taiwan \\ ${ }^{\ddagger}$ National Synchrotron Radiation Research Center, Hsinchu 30076, Taiwan \\ ${ }^{\S}$ Center for Nanophase Materials Sciences and ${ }^{\|}$Materials Science and Technology Division, Oak \\ Ridge National Laboratory, Oak Ridge, Tennessee 37831-6496, United States \\ ${ }^{\perp}$ Department of Materials and Mineral Resources Engineering, National Taipei University of \\ Technology, Taipei 10608, Taiwan
}

*To whom correspondence should be addressed. E-mail: chunhong@gate.sinica.edu.tw

S.-C. H. and Y.-C. C. contributed equally to this work

\section{Experimental details}

\section{Chemicals}

Hydrogen tetrachloroaurate trihydrate $\left(\mathrm{HAuCl}_{4} \cdot 3 \mathrm{H}_{2} \mathrm{O}, 99+\%\right.$, Sigma-Aldrich), sodium citrate dihydrate $\left(\mathrm{C}_{6} \mathrm{H}_{5} \mathrm{Na}_{3} \mathrm{O}_{7} \cdot 2 \mathrm{H}_{2} \mathrm{O}, 99+\%\right.$, J. T. Baker), palladium (II) chloride $\left(\mathrm{PdCl}_{2}, 99+\%\right.$, UniRegion biotech), hexadecyltrimethylammonium bromide $\left(\mathrm{CH}_{3}\left(\mathrm{CH}_{2}\right)_{15} \mathrm{~N}(\mathrm{Br})\left(\mathrm{CH}_{3}\right)_{3}, \mathrm{CTAB}, 98 \%\right.$, TCI), hexadecyltrimethylammonium chloride $\left(\mathrm{CH}_{3}\left(\mathrm{CH}_{2}\right)_{15} \mathrm{~N}(\mathrm{Cl})\left(\mathrm{CH}_{3}\right)_{3}, \mathrm{CTAC}, 95 \%\right.$, TCI), and Palladium Catalysts $(<100 \mathrm{~nm},>99.9 \%$, Aldrich) were used without further purification. Ultrapure deionized water $\left(18.2 \mathrm{M} \Omega \mathrm{cm}^{-1}\right)$ was used for all solution preparations.

\section{Preparation of Precursor Solutions}

Prior to all synthetic steps, aqueous solutions of $10 \mathrm{mM} \mathrm{HAuCl} 4,100 \mathrm{mM}$ sodium citrate, $15 \mathrm{mM}$ CTAC and $15 \mathrm{mM}$ CTAB were prepared with DI water at room temperature. $\mathrm{The}_{2} \mathrm{PdCl}_{4}(10 \mathrm{mM})$ aqueous solution was prepared by completely dissolving $\mathrm{PdCl}_{2}(17.7 \mathrm{mg})$ in $\mathrm{HCl}(0.02 \mathrm{M}, 10 \mathrm{~mL})$ with heating at $60{ }^{\circ} \mathrm{C}$ in an oil bath, followed by cooling to room temperature.

\section{Synthesis of Au-Pd Alloy Icosahedral Nanocrystals}

$43.66 \mathrm{~mL}$ of $15 \mathrm{mM} \mathrm{CTAB}, 4.85 \mathrm{~mL}$ of $15 \mathrm{mM} \mathrm{CTAC}, 0.625 \mathrm{~mL}$ of $10 \mathrm{mM} \mathrm{HAuCl}_{4}, 0.625 \mathrm{~mL}$ of $10 \mathrm{mM} \mathrm{H}_{2} \mathrm{PdCl}_{4}$, and $237.5 \mu \mathrm{L}$ of $100 \mathrm{mM}$ sodium citrate were mixed in a glass vessel with a volume capacity of $100 \mathrm{~mL}$. A Teflon-lined polypropylene cap with an O-ring was used for sealing. The vessel was placed in an oven set at $90{ }^{\circ} \mathrm{C}$ for 16 hours.

Synthesis of Au-Pd Core-Shell Icosahedral Nanocrystals

$12.13 \mathrm{~mL}$ of $15 \mathrm{mM} \mathrm{CTAB}, 36.38 \mathrm{~mL}$ of $15 \mathrm{mM} \mathrm{CTAC}, 0.625 \mathrm{~mL}$ of $10 \mathrm{mM} \mathrm{HAuCl}_{4}, 0.625 \mathrm{~mL}$ of 
$10 \mathrm{mM} \mathrm{H}_{2} \mathrm{PdCl}_{4}$, and $237.5 \mu \mathrm{L}$ of $100 \mathrm{mM}$ sodium citrate were mixed in a glass vessel with a volume capacity of $100 \mathrm{~mL}$. A Teflon-lined polypropylene cap with an O-ring was used for sealing. The vessel was placed in an oven set at $90{ }^{\circ} \mathrm{C}$ for 16 hours.

\section{Synthesis of Pd Icosahedral Nanocrystals}

The synthesis is referred to the previous work. ${ }^{1} 27.75 \mathrm{~mL}$ of DI water was added to a $100 \mathrm{~mL}$ vessel that contained $123.75 \mathrm{mg}$ of CTAB followed by sonication to completely dissolve the CTAB. Next, $0.75 \mathrm{~mL}$ of $10 \mathrm{mM} \mathrm{Na} 2 \mathrm{PdCl}_{4}$ solution was added along with $1.5 \mathrm{~mL}$ solution of $0.1 \mathrm{M}$ citric acid. After mixing well, the glass vessel was sealed with Teflon-lined polypropylene cap with an O-ring and left to stand in an oven at $110{ }^{\circ} \mathrm{C}$ for $22 \mathrm{~h}$.

\section{Characterization}

To prepare samples for characterization, washing and concentrating by centrifuging had to be carried out. In typical, all products were collected at 11000 r.p.m. for $20 \mathrm{~min}$ followed by removing the supernatant. After adding fresh DI water to reach the original volume, centrifuging was done again to rinse the dispersions. The washing step was repeated twice. Finally, the collected products were re-dispersed to $200 \mu \mathrm{L}$ and stored in a $1.5 \mathrm{~mL}$ centrifuge tube. To prepare samples for SEM or TEM, $5 \mu \mathrm{L}$ of concentrated sample solutions was dropped onto silicon wafers in the size of $0.3 \times 0.3 \mathrm{~cm}^{2}$ or carbon-coated copper grids with slowly drying at room temperature. Centrifuging steps were done using Eppendorf Centrifuge 5804 and Thermo Scientific Heraeus Pico 17. SEM images were recorded by a ZEISS ULTRA PLUS equipped with an OXFORD EDX detector, operated at the accelerating voltage of $10 \mathrm{KeV}$. Low- and high-magnification TEM bright-field images were taken by a JEOL JEM-2100F microscope operating at $200 \mathrm{kV}$. HAADF-STEM-EDS imaging and element maps were acquired using an FEI Talos F200X STEM operated at $200 \mathrm{kV}$, which takes advantage of a system of four orthogonal EDS detector units for high collection efficiency. Aberration-corrected HAADF-STEM imaging were conducted on a JEOL 2200FS-AC STEM operated at 200kV. UV-Vis absorption spectra were measured on a HITACHI U-3310 spectrophotometer. The X-ray diffraction experiments were performed at BL01C2 in National Synchrotron Radiation Research Center (NSRRC). The diffraction data were collected using $18 \mathrm{keV} \mathrm{X-rays} \mathrm{(0.68888} \mathrm{\AA} \mathrm{in} \mathrm{wavelength)} \mathrm{and}$ Mar345 image plate detector with Debye-Scherrer geometry. The patterns were converted by GSAS-II program and the angle calibration was performed according to LaB6 (SRM 660c) standard. ${ }^{2}$ The atomic contents of Au-Pd alloy and core-shell icosahedral nanocrystals were measured using Varian 720-ES, the ICP optical emission spectrometer (ICP-OES). For the measurement, the nanocrystals were dissolved with aqua regia and diluted to ppm level in concentration.

\section{Ethanol Electrooxidation}

All electrical measurements were carried out in a standard three-electrode cell using an 
electrochemical workstation (CHI 705E). To prepared the catalyst-loaded working electrodes, $5 \mu \mathrm{L}$ of the $200 \mu \mathrm{L}$ nanocrystal solutions was dropped on a bare glassy carbon electrode (GCE). Then, 3 $\mu \mathrm{L}$ of $0.05 \%$ nafion aqueous solution was spread on the catalysts and thoroughly dried. Steps of loading the commercial Pd catalysts on the GCE were mostly the same except for the particle solution was in the concentration of $5 \mathrm{mg} / \mathrm{mL}$. A KCl-saturated $\mathrm{Hg} / \mathrm{Hg}_{2} \mathrm{Cl}_{2}$ electrode was used as the reference electrode and a $\mathrm{Pt}$ wire as the counter electrode, respectively. The blank scan of the catalyst-loaded GCE was run in a cyclic voltammetry $(\mathrm{CV})$ mode at a scanning rate of $50 \mathrm{mV} \mathrm{s}^{-1}$ in a $0.5 \mathrm{M} \mathrm{KOH}$ electrolyte solution (Ar pre-purging for 30 minutes) at room temperature until the CV-curve went stable. The ECSA was determined by integration of the total charge collected from the $\mathrm{PdO}$ reduction peak (as marked in Figure S13) and dividing the value by the charge per area $\left(0.42 \mathrm{mC} / \mathrm{cm}^{2}\right)$. For ethanol electrooxidation, sweeping in the $\mathrm{CV}$ mode within the range of -0.8 $\mathrm{V} \sim 0.4 \mathrm{~V}$ at a scan rate of $50 \mathrm{mV} \mathrm{s}^{-1}$ was conducted in the $0.27 \mathrm{M}$ ethanol/0.5 M KOH electrolyte at room temperature. The durability test was carried out in the chronoamperometric i-t mode by sweeping at $-0.1 \mathrm{~V}$ for 1 hour.

\section{4-nitrophenol Catalytic Reduction}

The 4-nitrophenol (4-NP) reduction was performed to test the light-enhanced effect in the catalytic activity by monitoring the degradation of the 4-NP featured absorption peak (400 nm). In typical, a solution containing $2.78 \mathrm{~mL}$ of DI water, $3.72 \mu \mathrm{g}$ of catalysts, $0.2 \mathrm{~mL}$ of $0.1 \mathrm{M} \mathrm{NaBH}_{4}$, and $0.02 \mathrm{~mL}$ of $0.01 \mathrm{M}$ 4-nitrophenol was prepared in a quartz cuvette with an inner edge length of $1 \mathrm{~cm}$. The cuvette was placed in a water bath controlled at a constant temperature $25{ }^{\circ} \mathrm{C}$ throughout the reaction. The reaction was carried out in dark and under the visible light irradiation using a Xe lamp providing a true incident light power of $550 \mathrm{~mW}$ to the sample at the irradiated distance of $10 \mathrm{~cm}$. HITACHI U-3310 UV-visible spectrometer was set to monitor the absorbance in the range of 250 to $550 \mathrm{~nm}$ where the $\lambda_{\max }$ of 4-NP is at $400 \mathrm{~nm}$ and $4-\mathrm{AP}$ at $305 \mathrm{~nm}$. Pre-stirring at the first 10 minutes were not counted in the data recording to avoid the interference of 4-NP adsorption on particle surfaces.

\section{References}

1. C.-H. Kuo, L. K. Lamontagne, C. N. Brodsky, L.-Y. Chou, J. Zhuang, B. T. Sneed, M. K. Sheehan, C.-K. Tsung, "The Effect of Lattice-Strain on the Catalytic Properties of Pd Nanoparticles", ChemSusChem 2013, 6, 1993-2000.

2. B. H. Toby and R. B. Von Dreele, "GSAS-II: the genesis of a modern open-source all purpose crystallography software package”, J. Appl. Crystallogr. 2013, 46, 544-549. 

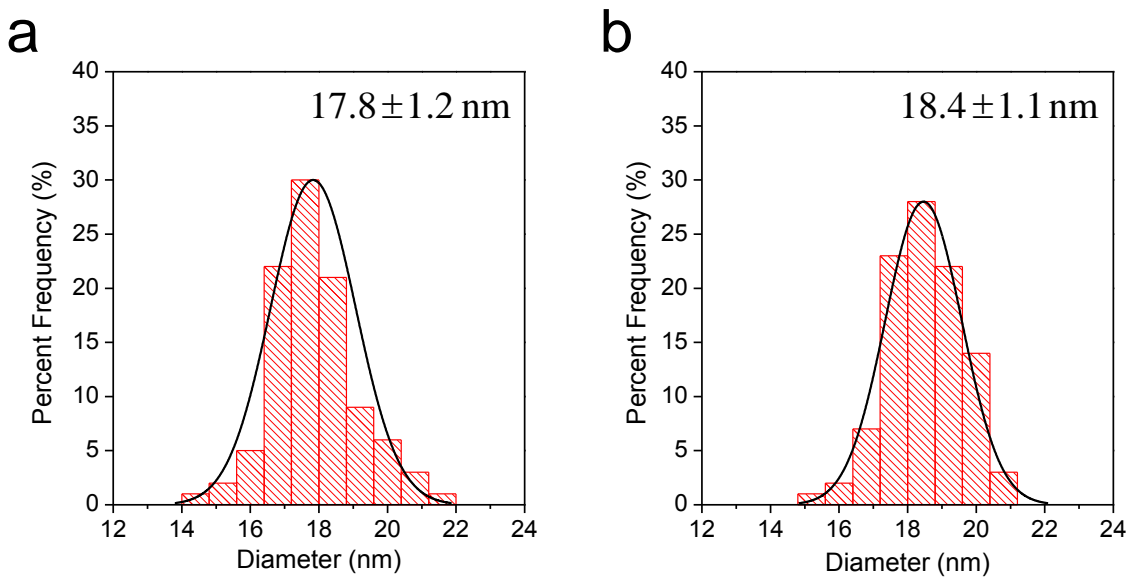

Figure S1. Size histograms of Au-Pd (a) alloy and (b) core-shell icosahedral nanocrystals show narrow ranges of their distributions. The percent deviations for each are $6.74 \%$ (alloy) and $5.98 \%$ (core-shell), respectively.

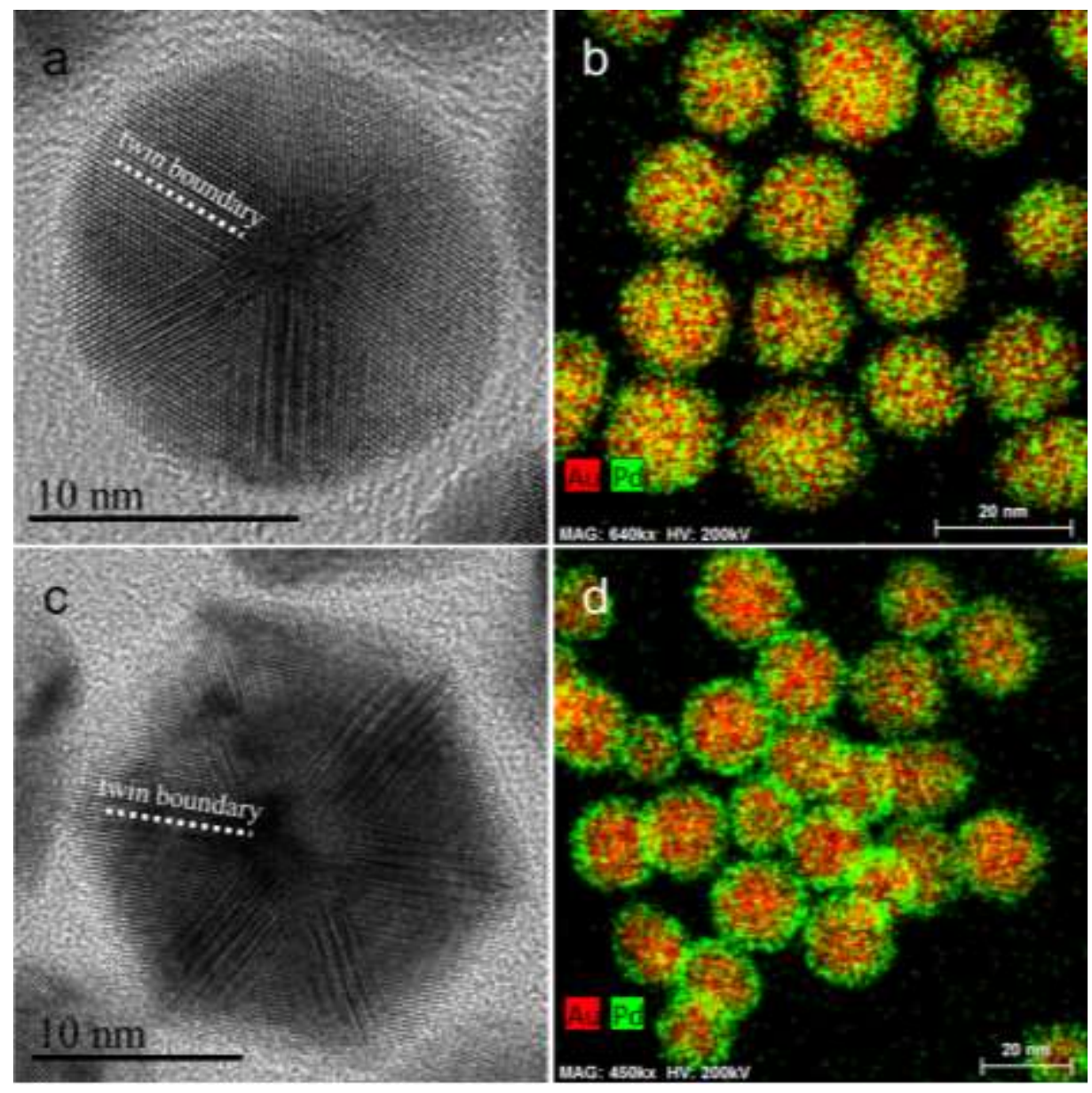

Figure S2. The high-resolution TEM images of an individual Au-Pd (a) alloy and (c) core-shell IH nanocrystals. (b,d) Their corresponding low-magnification EDS mapping images. 


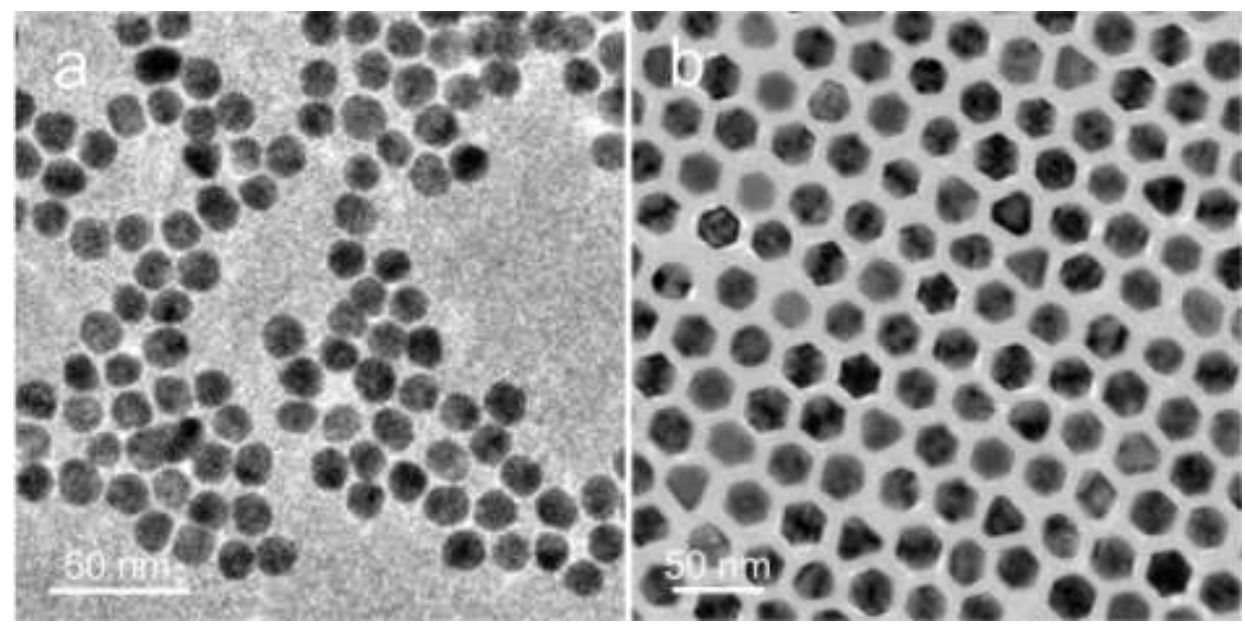

Figure S3. TEM images of (a) Au and (b) Pd IH nanocrystals for the XRD references.
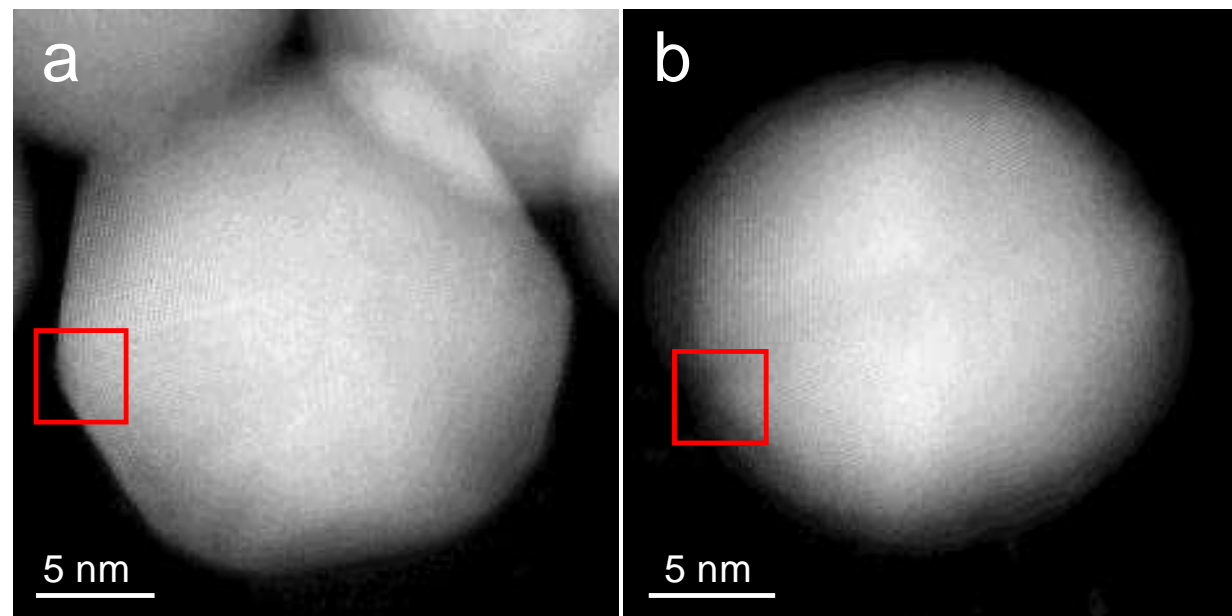

Figure S4. Aberration-corrected HAADF-STEM images of an individual (a) alloy and (b) core-shell IH nanocrystals.

Table S1. The summary of Au and Pd compositions in the alloy and core-shell nanoicosahedra.

\begin{tabular}{ccccc} 
& \multicolumn{2}{c}{ Alloy } & \multicolumn{2}{c}{ Core-Shell } \\
& $\mathrm{Au}(\%)$ & $\mathrm{Pd}(\%)$ & $\mathrm{Au}(\%)$ & $\mathrm{Pd}(\%)$ \\
\hline XRD & 79 & 21 & 84 & 16 \\
\hline ICP-OES & 79.44 & 20.56 & 78.45 & 21.55 \\
\hline
\end{tabular}



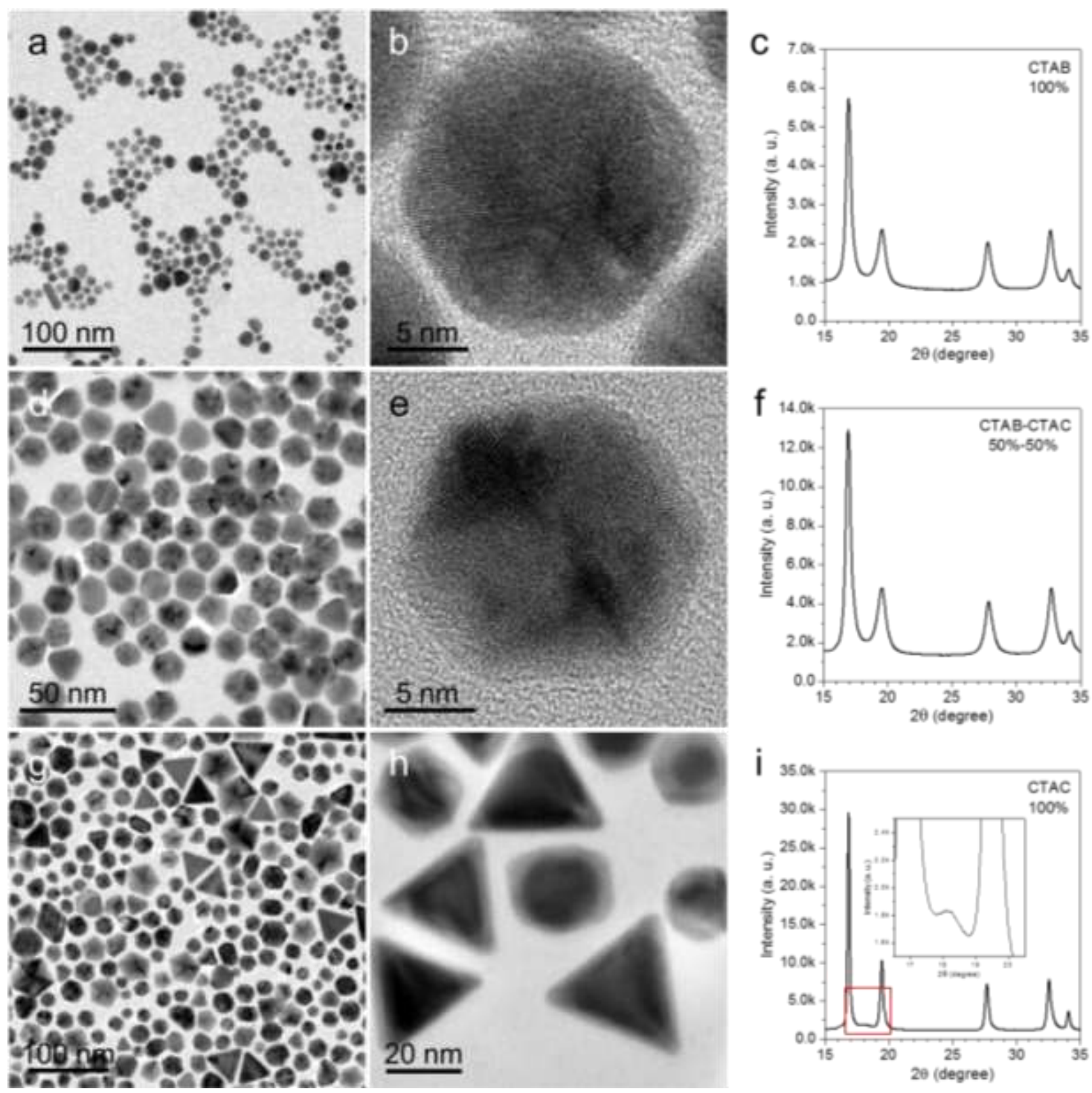

Figure S5. TEM images and XRD patterns of the Au-Pd nanocrystals made with (a-c) pure CTAB, (d-f) equally mixed CTAB/CTAC, and (g-i) pure CTAC. 


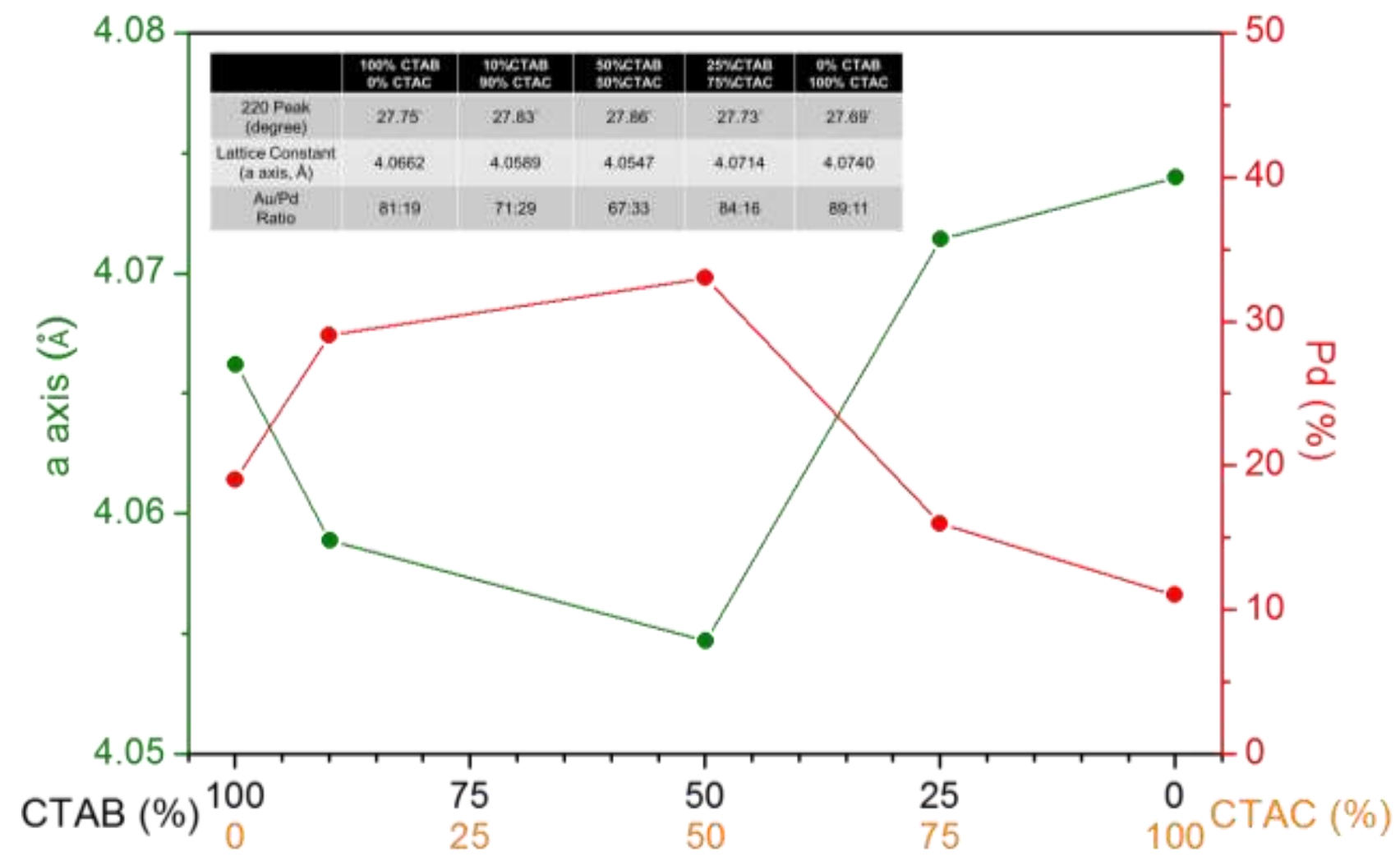

Figure S6. The plots of lattice constant (a axis in fcc) and Pd content of the cores vs CTAB/CTAC ratio. The lattice constants of $\mathrm{Au}$ and $\mathrm{Pd} \mathrm{IH}$ nanocrystals are 4.0839 and $3.9852 \AA$, respectively.

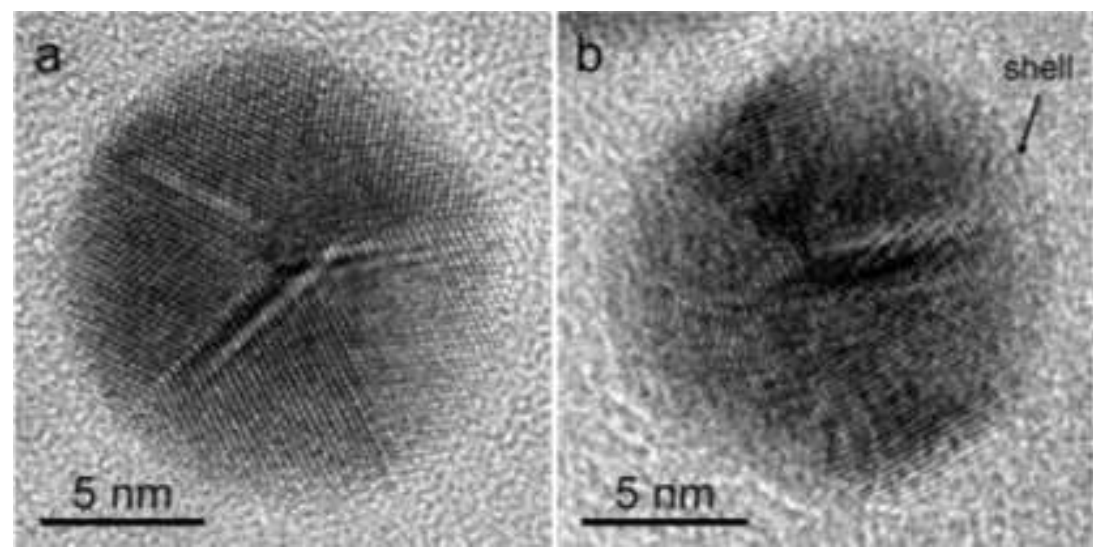

Figure S7. TEM images of Au-Pd (a) alloy and (b) core-shell IH nanocrystals obtained by purging their precursor solutions with Ar for 30 minutes before heating. 

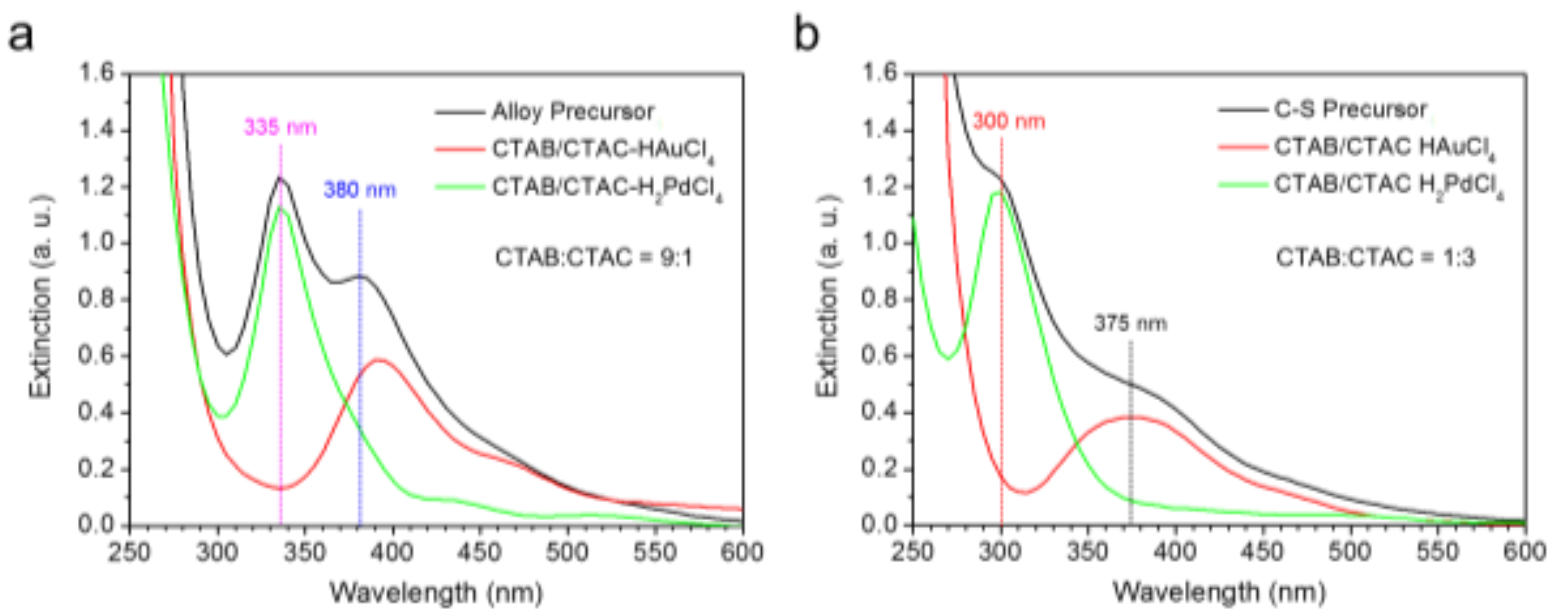

Figure S8. UV-vis spectra of precursor solutions $\left(\mathrm{HAuCl}_{4} / \mathrm{H}_{2} \mathrm{PdCl}_{4}=1\right)$ from the synthesis conditions of (a) alloy and (b) core-shell IH nanocrystals. The references for comparison are those prepared by dissolving $\mathrm{HAuCl}_{4}$ or $\mathrm{H}_{2} \mathrm{PdCl}_{4}$ in the corresponding $\mathrm{CTAB} / \mathrm{CTAC}$ mixed solutions, respectively.

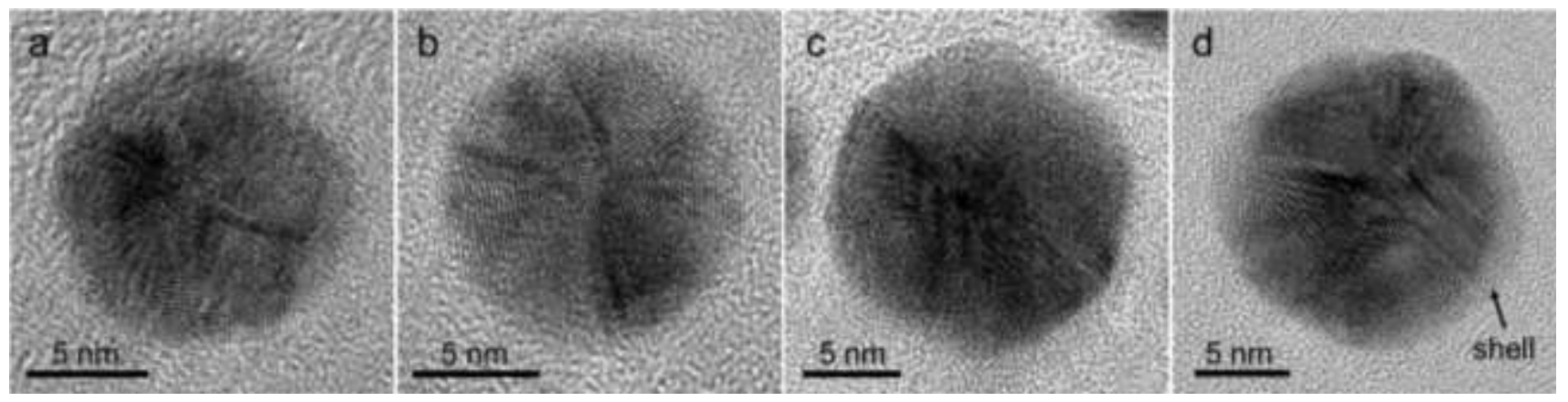

Figure S9. The HRTEM images of the intermediates in the solutions of the core-shell IH nanocrystals recorded at (a) 3rd, (b) 5th, (c) 8th and (d) 12th hour during synthesis. These images present a steady process of size growth, IH shape optimization, and shell evolution.

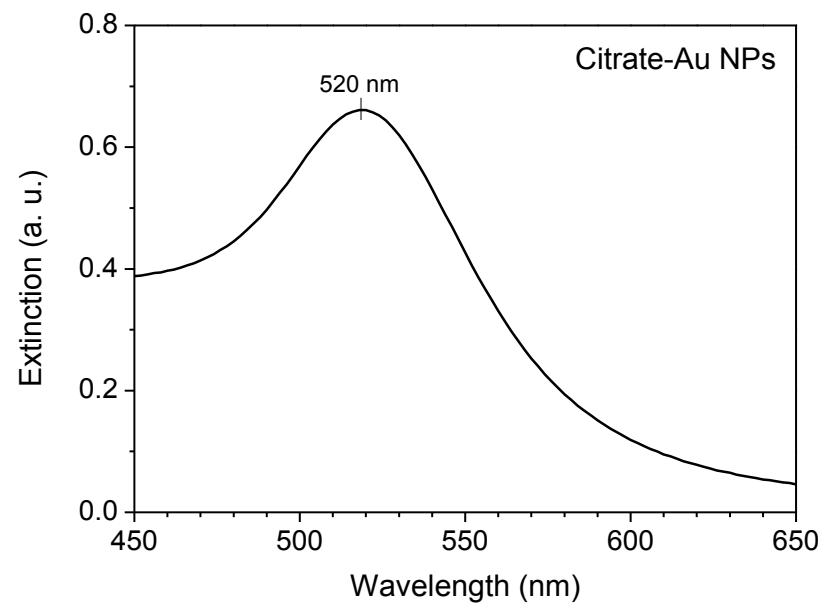

Figure S10. The UV-vis spectrum of citrate-Au icosahedral nanocrystals $\sim 13 \mathrm{~nm}$ in diameter. 

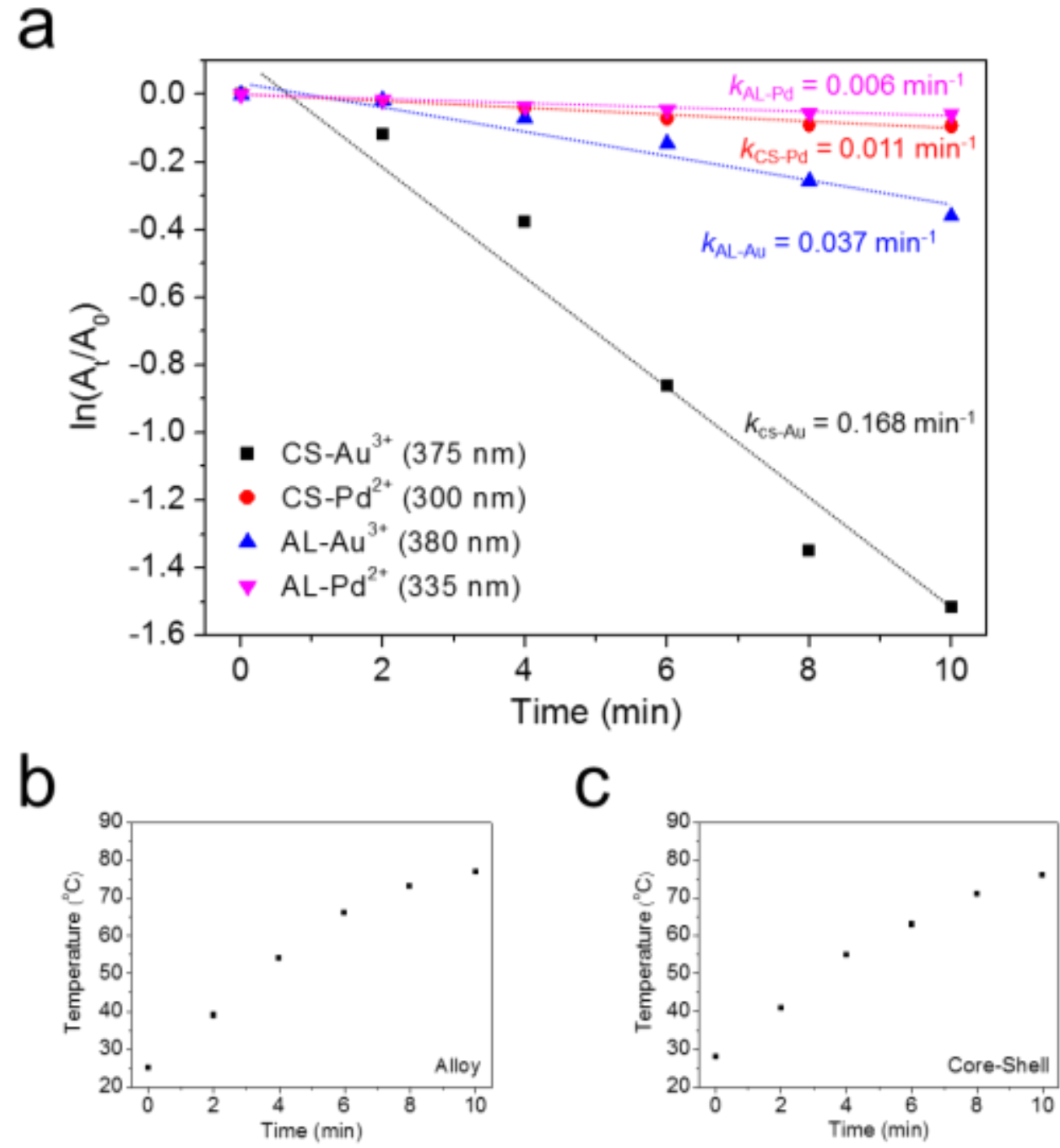

Figure S11. (a) $\ln \left(\mathrm{A}_{t} / \mathrm{A}_{0}\right)$ vs time plot of $\mathrm{Au}$ and $\mathrm{Pd}$ precursors in the two cases of alloy and core-shell IH nanocrystals. The kinetic measurement was carried out by tracking the absorption drops at specific wavelengths according to Figure S8. (b,c) Temperature variation in 10 minutes in both cases of alloy and core-shell IHs. 

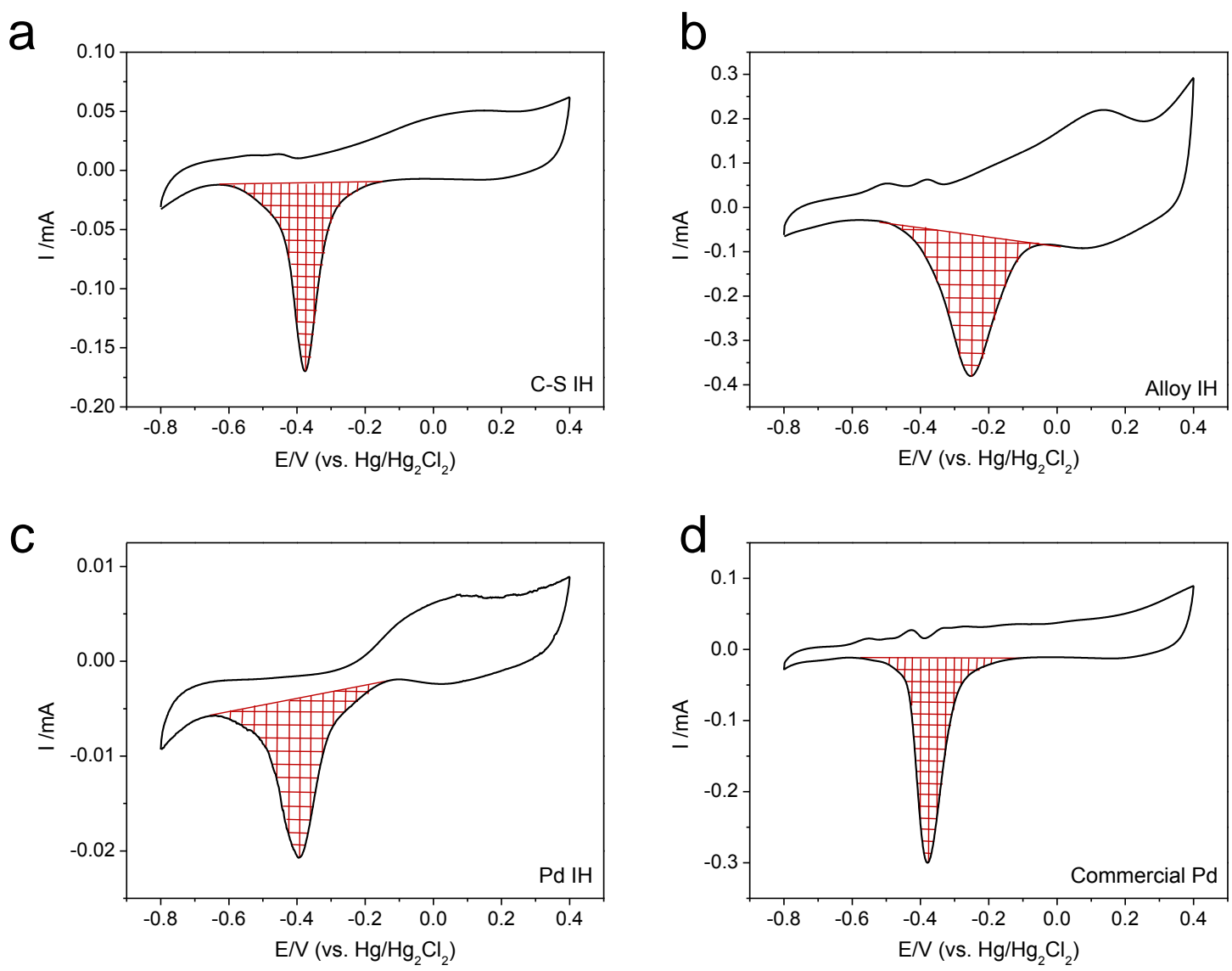

Figure S12. CVs of the blanking scan with (a) Au-Pd core-shell, (b) alloy, (c) Pd IH and (d) commercial Pd catalysts. The integrated area of the peaks was used to determine their electrochemically active surface areas.

a

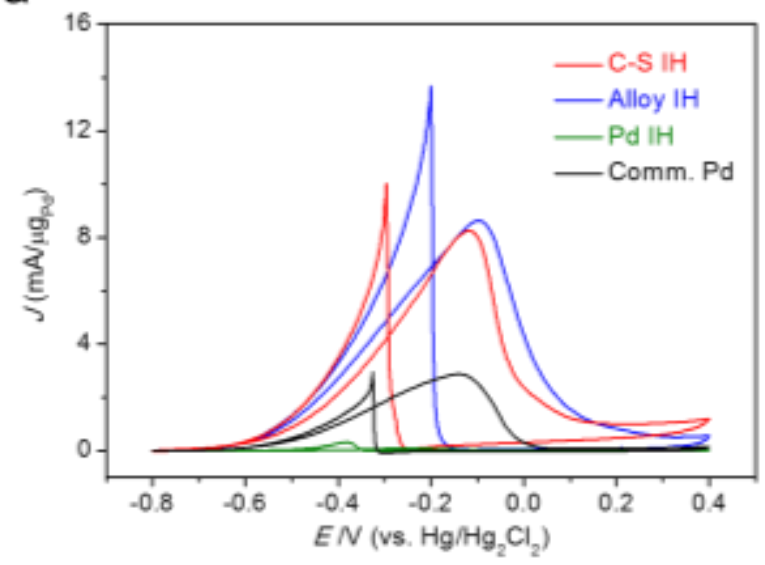

b

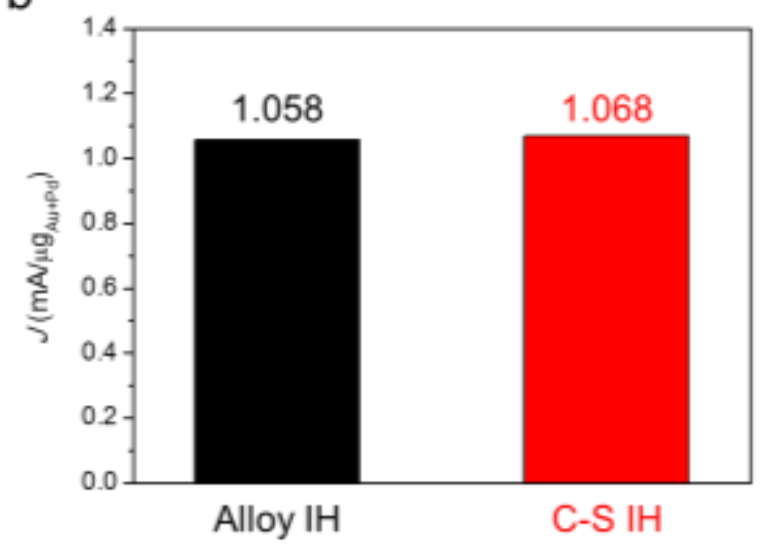

Figure S13. (a) CVs of Au-Pd core-shell, alloy, Pd IH and commercial Pd catalysts on a GCE in 0.27 $\mathrm{M} \mathrm{EtOH}+0.5 \mathrm{M} \mathrm{KOH}$. Current values were normalized with respect to Pd mass determined by ICP-OES. (b) The column-chart summary of the total mass activities of the alloy and core-shell IH catalysts. 

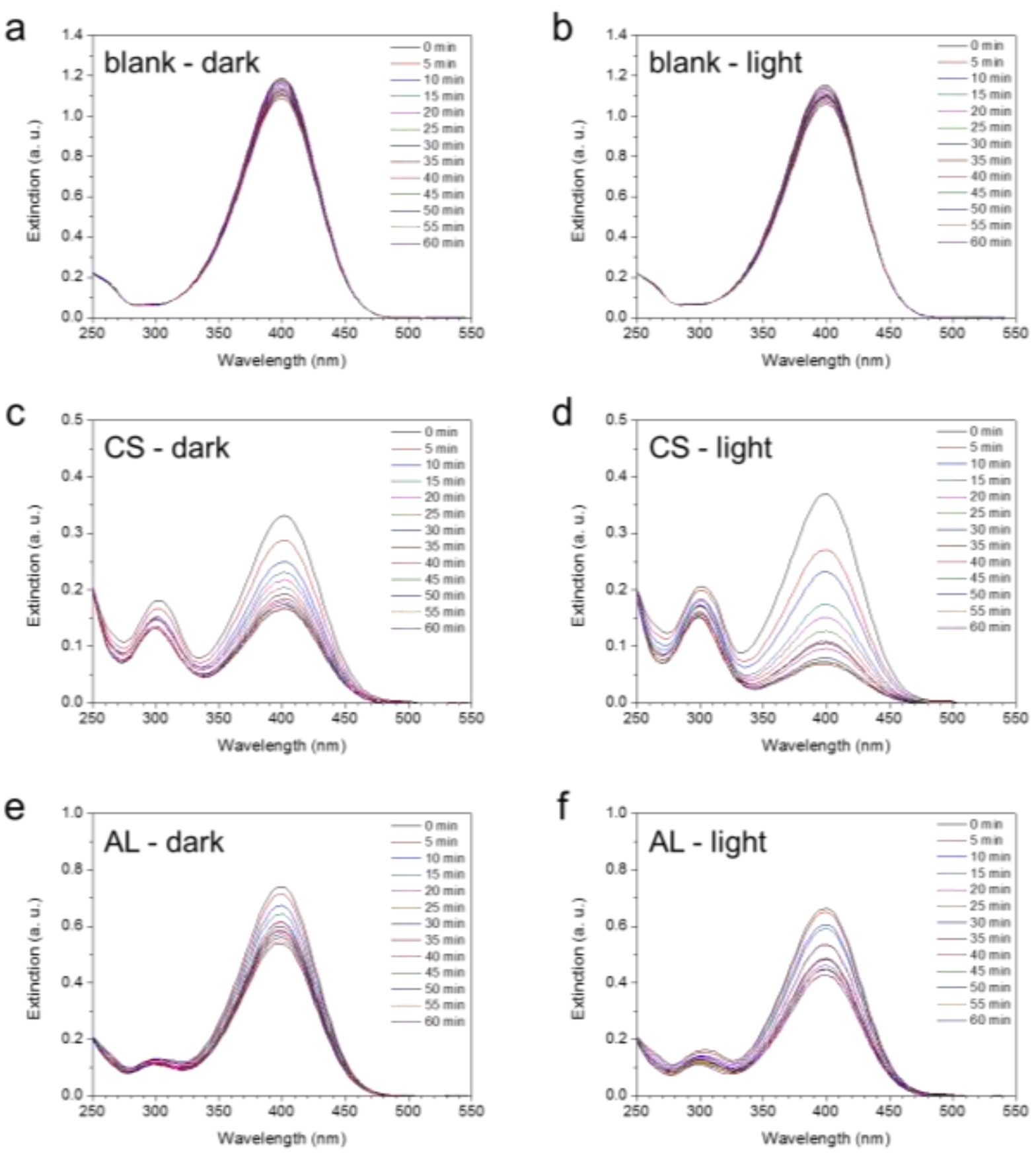

Figure S14. Time-dependent UV-vis spectra of 4-nitrophenol reduction. (a,b) Blank test without catalysts. (c,d) Core-shell IH-catalyzed reduction. (e,f) Alloy IH-catalyzed reduction. 


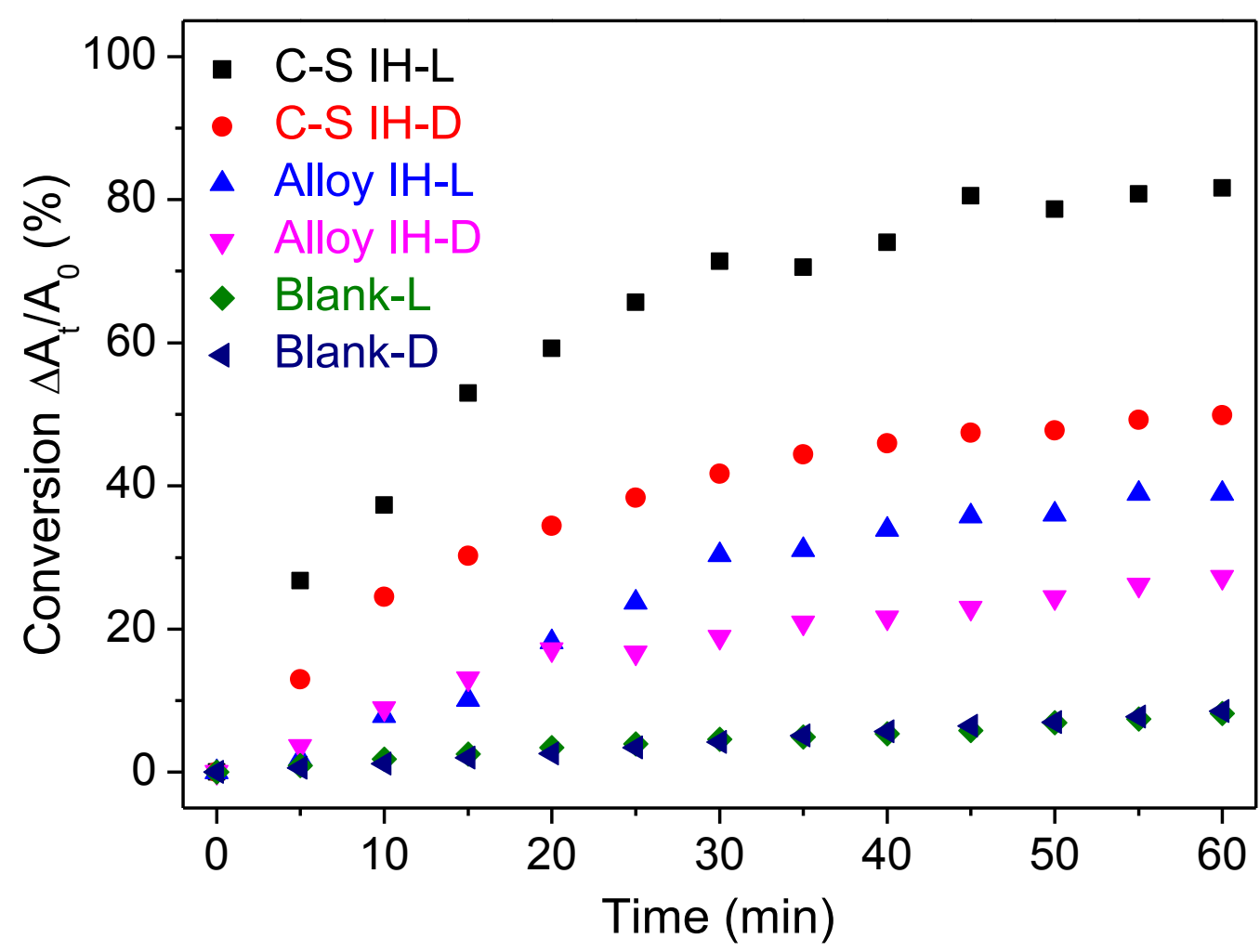

Figure S15. The plot of conversion vs time. A denotes the absorbance. The $\Delta \mathrm{A}_{t}$ is equal to $\mathrm{A}_{0}-\mathrm{A}_{\mathrm{t}}$.

Table S2. The summary of the reaction rates and conversions of 4-nitrophenol reduction.

\begin{tabular}{|c|c|c|c|}
\hline \multirow{2}{*}{ Condition } & \multicolumn{2}{|c|}{ Reaction Rate $k\left(\mathrm{~min}^{-1}\right)$} & \multirow{2}{*}{ Conversion (\%) } \\
\cline { 2 - 3 } & $0-30 \mathrm{~min}$ & $30-60 \mathrm{~min}$ & 81.6 \\
\hline CS IH-L & $43.8 \times 10^{-3}$ & $17.1 \times 10^{-3}$ & 49.8 \\
\hline CS IH-D & $17.5 \times 10^{-3}$ & $4.8 \times 10^{-3}$ & 38.9 \\
\hline Alloy IH-L & $12.2 \times 10^{-3}$ & $4.7 \times 10^{-3}$ & 27.3 \\
\hline Alloy IH-D & $7.3 \times 10^{-3}$ & $3.6 \times 10^{-3}$ & 8.5 \\
\hline Blank-L & \multicolumn{2}{|c|}{$1.4 \times 10^{-3}$} & 8.5 \\
\hline Blank-D & \multicolumn{2}{|c|}{$1.4 \times 10^{-3}$} \\
\hline
\end{tabular}

